\title{
Andra världskrigets ruinstäder och dess betydelse för svarta rödstjärtens Phoenicurus ochruros expansion i norra Europa
}

\author{
The Second World War ruined cities and their importance for the expansion of the \\ Black Redstart Phoenicurus ochruros in northern Europe
}

REINO ANDERSSON

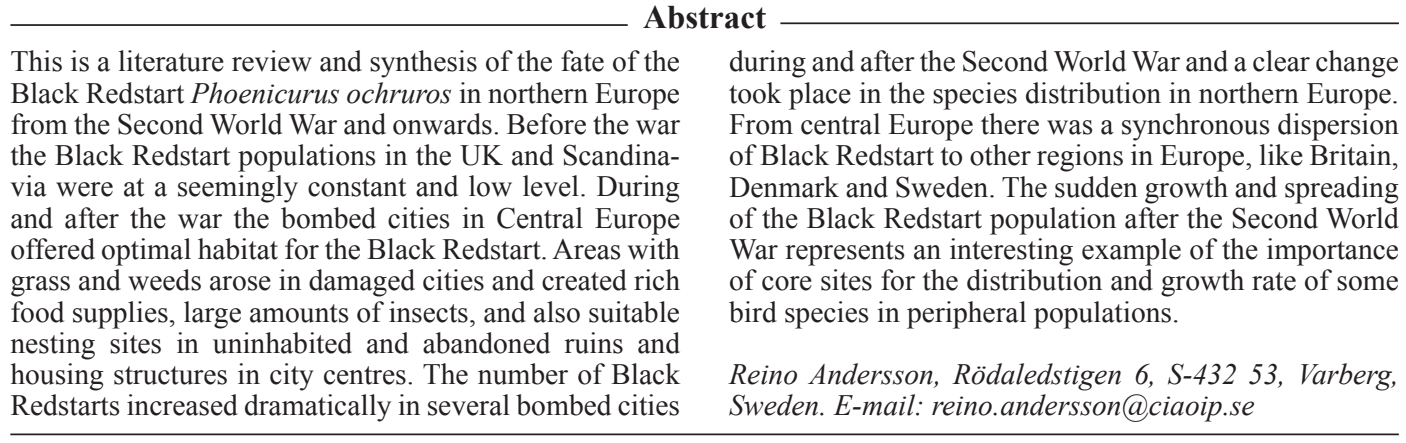

Received 4 December 2014, Accepted 8 April 2015, Editor: Å Lindström

\section{Inledning}

Svarta rödstjärten Phoenicurus ochruros expanderade långsamt norrut i Europa under 1800-talet. I södra och mellersta Tyskland var den en vanlig häckfågel redan i mitten av århundradet. I Nordtyskland betecknades den däremot ännu på 1880-talet som sparsam och exempelvis Hamburgs äldre fågelfaunor redovisar endast enstaka häckningsfynd (Rosenius 1926, Wittenberger 1976, Glutz \& Bauer 1988). Den förekom sällsynt i Nederländerna men saknades fortfarande som häckfågel i Storbritannien (Fitter 1955, Vleugel 1960 a, b, Glutz \& Bauer 1988). Även de danska häckfynden var vid denna tidpunkt fåtaliga och koncentrerade till sydligaste Jylland (Malling Olsen 1992). Den första bekräftade häckningen i Sverige dateras till Mörarp i Skåne 1900 och åren därpå återfanns ytterligare några par exempelvis vid sockerbruk i Helsingborg (Borén 1903). Tidsperioden fram till andra världskriget höll sig sedan numerären till synes oförändrade på samma låga nivå (Rosenius 1926, Curry-Lindahl 1963).

Denna uppsats belyser den svarta rödstjärtens status i städer som blev sönderbombade under krigsåren 1940-1945 och dess betydelse för artens fortsatta expansion. De uppkomna biotopernas po- tentiella inverkan på svarta rödstjärtens vidgade utbredning är av stort intresse ur flera aspekter, bland annat då det visar hur viktig utvecklingen $\mathrm{i}$ kärnområdena är för spridningsförloppet till mer perifera populationer. Att svarta rödstjärten gynnades av ruinmiljöerna som uppstod under kriget har tidigare uppmärksammats av t.ex. Schumann (1956), Meadows (1970) och Wittenberger (1976). Detta är dock den första mer detaljerade sammanställningen med fokus på dess betydelse för artens fortsatta expansion i norra Europa.

\section{Metoder}

För att erhålla en så fullständig bild som möjligt har en grundlig litteraturgenomgång gjorts av publicerade artiklar om svart rödstjärt. Även en mängd tyska, holländska och engelska lokalfaunor där svarta rödstjärten behandlas har granskats. Likaså har faunistiska uppgifter från Sverige, Danmark och Norge sammanställts för att kunna se ett eventuellt spridningsmönster kopplat till andra världskriget. Ett stort antal fotografier av de sönderbombade städerna har studerats på Internet, för att få en mer detaljerad bild av hur husruinerna kan tänkas ha gynnat arten. Materialet kommer från ett 
stort antal källor och informationen är av naturliga skäl inte lika detaljerad som den faunistiska information som samlas in idag. Samtidigt saknas i stort sett uppgifter i t.ex. Glutz \& Bauer (1988) från vissa geografiska områden som också utsattes för omfattande bombningar, exempelvis Polen. Polsk ornitologisk litteratur har dock inte genomsökts för denna uppsats.

De uppkomna biotopernas gynnsamhetsgrad bedömdes visuellt med den så kallade flikighetsgraden (Andersson 1995). Flikighetsgraden har tidigare använts på svenska biotoper $\mathrm{i}$ en tregradig skala (låg, medel, hög) som ett grovt mått på bebyggelsens trasighet, vilket är av betydelse bl.a. för tillgången på skydd och boplatser. Låg innebär att mindre än en tredjedel av reviret uppvisade flikighet, medel motsvarade ungefär hälften och hög att mer än två tredjedelar var flikigt. Enligt en likartad skala bedömdes tillgången på stora och höga byggnader i ruinstäderna. Sådana kan tänkas ha en dragningskraft på hannarna med höga sångposter. Likaså uppskattades arealen ogräs/ruderatmark utifrån de fotografier som funnits tillgängliga, vilket kan ses som ett annat mått på revirkvaliteten med avseende på födotillgången $\mathrm{i}$ form av insekter (Andersson 1995).

\section{Resultat}

\section{Situationen i de sönderbombade städerna}

Enbart i Tyskland blev drygt 160 städer och 850 mindre orter sönderbombade och många av dem ödelades nästan helt (Friedrich 2008, Figur 1).

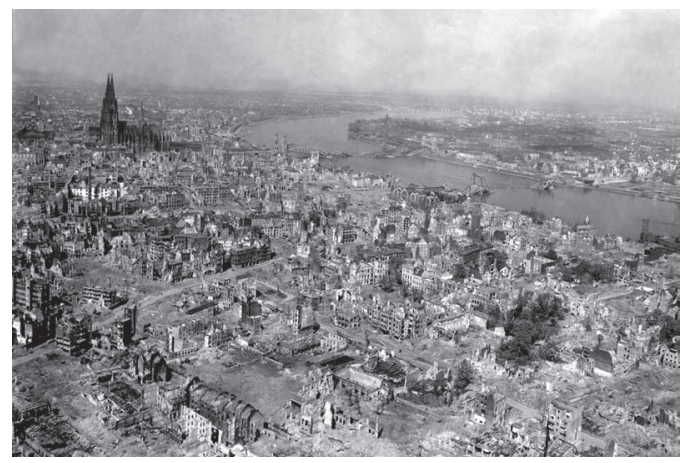

Figur 1. I Europas sönderbombade städer fann svarta rödstjärten optimala biotoper för födosök och bobyggnad. Köln 1945 (hämtat från Wikipedia, http://en.wikipedia.org/wiki/ Bombing_of_Cologne_in_World_War_II).

In the bombed cities in Europe, the Black Redstart found optimal habitats for feeding and nest building. Köln 1945 (from Wikipedia).

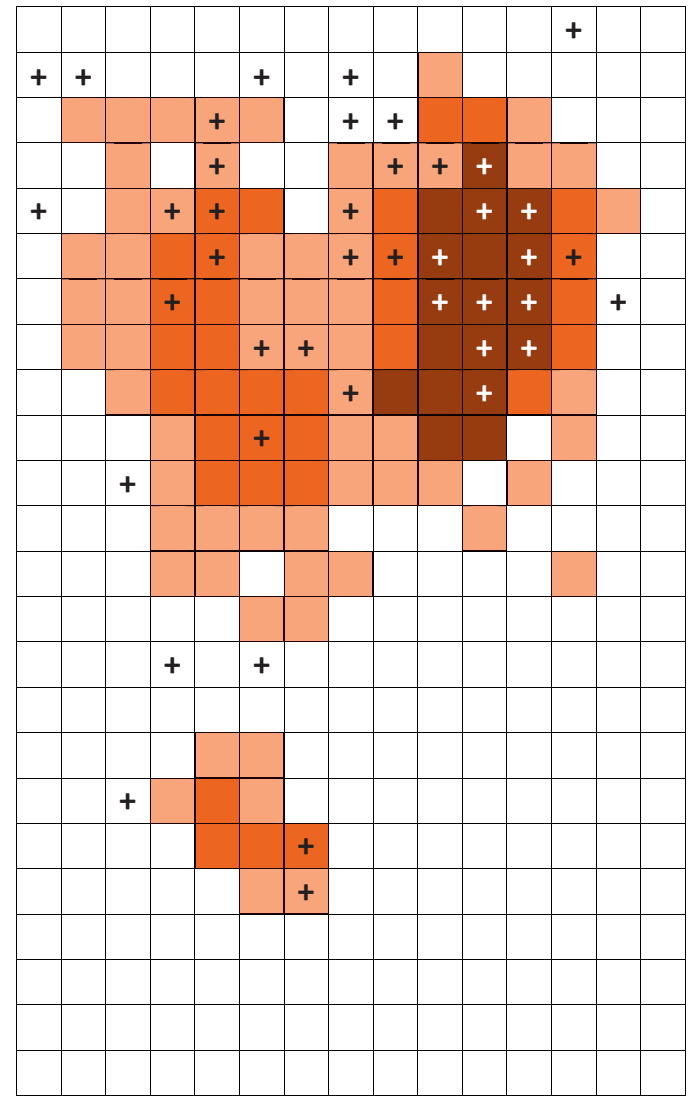

Figur 2. Utbredningen av bombad bebyggelse vid krigsslutet i Hamburg samt revir av svart rödstjärt i samma område 1944-1963. Nyansen i de färgade rutorna (c. 1x1 km) markerar graden av förstörelse: totalförstört (mörkast), ungefär hälften förstört (mellannyans) och mindre än hälften förstört (ljusast färg). Plustecken anger revir av svart rödstjärt. Omritat efter Wittenberger (1976).

The distribution of ruins at the end of the war after bombing in Hamburg and territories of Black Redstart in 1944-1963. The colour intensity of a square $(c .1 \times 1 \mathrm{~km})$ indicates the level of destruction: total destruction (darkest), about half of the buildings destroyed (intermediate), and less than half destroyed (lightest shade). Re-drawn after Wittenberger (1976).

Svarta rödstjärten angavs som ruinhäckare på många håll, bland annat i Hamburg (Timmermann 1953, Lemke 1965, Wittenberger 1976), Kiel (Schmidt 1953), Hannover (Schumann 1956), Berlin (Peus 1952, Wendland 1971), München (Wust 1970) och Westfalen (Muller 1969). Wittenberger (1976) beskriver utvecklingen i Hamburg, där han visar på svarta rödstjärtens ökning och koncentration till den förstörda stadskärnan (Figur 2-3). Även senare vid uppbyggnadsskedet under 1950- 


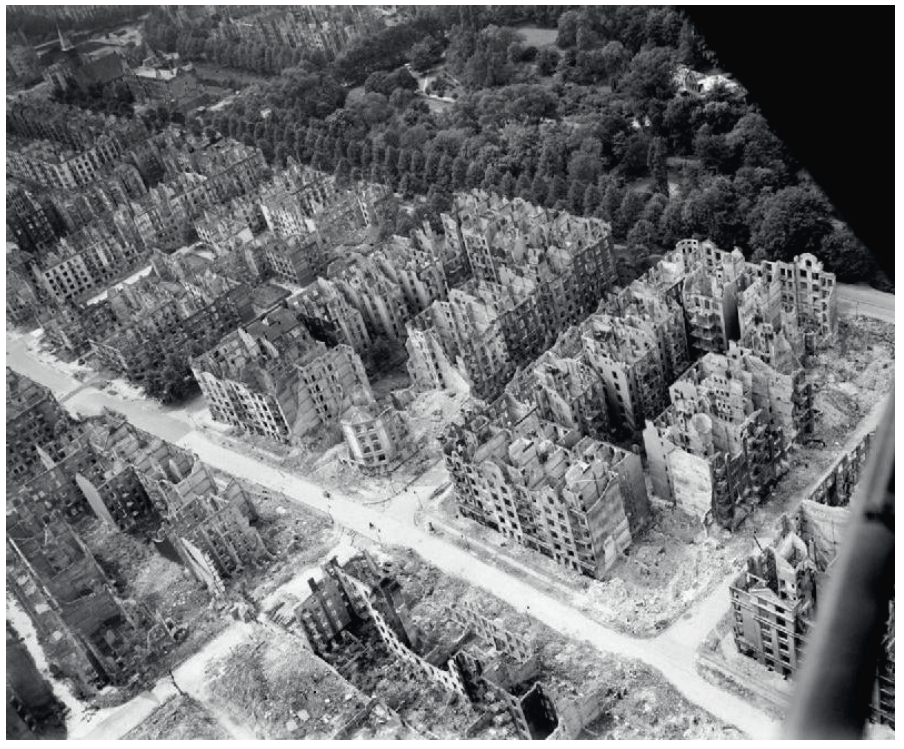

Figur 3. Sönderbombad stadsmiljö i Hamburg 1943 (hämtat från Wikipedia, http:// en.wikipedia.org/wiki/Bombing_of_Hamburg_in_World_War_II).

Bombed urban areas in Hamburg 1943 (from Wikipedia). och 1960-talet, erbjöd dessa områden optimala häckningsmiljöer. Från att ha haft höga tätheter där, blev efter återuppbyggnaden istället industriområden och bangårdar de bästa biotoperna för svarta rödstjärten. Exempel på sådan beståndsutveckling finns även från Göttingen där jämförbara inventeringar utförda 1948 och 1965 visade på en trefaldig ökning av numerären (Hampel \& Heitkamp 1968). Flikighetsgraden föreföll vara avsevärt högre än i de mest gynnsamma svenska stadsoch industrimiljöerna. Stora delar av de studerade städerna uppvisade genomgående hög flikighet och dominans av höga byggnader. Likaså uppgick andelen ogräs/ruderatmark i vissa fall till cirka $40 \%$ av arealen, vilket kan jämföras med att cirka 15\% krävdes för att ett häckrevir i Göteborgs stads- och industrimiljöer skulle anses optimalt (Andersson 1985, 1987, 1990, 1995).

I Nederländerna påträffades åtskilliga par i sönderbombade områden i Rotterdam och Haag 1943-1950, men arten minskade senare då städerna återuppbyggts (Vleugel 1960 a,b, Glutz \& Bauer 1988).

Även i Storbritannien skedde en markant ökning av antalet par i samband med bombningarna av framför allt London, men också vissa kustområden såsom Norfolk, Suffolk och Dover (Whitherby \& Fitter 1942, Fitter 1955, 1965, Meadows 1970, Allard 1973, Morgan \& Glue 1981, Glutz \& Bauer 1988). Från att ha hyst endast ett fătal par inräknades exempelvis totalt 49 sjungande hannar 1942 och drygt 60 hannar 1948. Antalen i London ökade till trettiotalet revir under 1940-talet, varav en mindre andel utgjordes av oparade hannar (Figur 4). De lägre antalen senare under 1950-talet anses delvis hänga samman med sämre bevakning. Vid en inventering 1975 registrerades totalt 104 revir i Storbritannien (Meadows 1970, Morgan \& Glue 1981).

\section{Utvecklingen i Skandinavien}

I Danmark var svarta rödstjärten ännu kring 1930 ytterst fåtalig som häckfågel. Efter krigsåren noterades en påfallande ökning av antalet par på allt fler lokaler. Åren 1966-1968 då inventeringar utfördes inräknades 65-95 par. Tio år senare bedömdes den danska häckpopulationen uppgå till 200 par, med

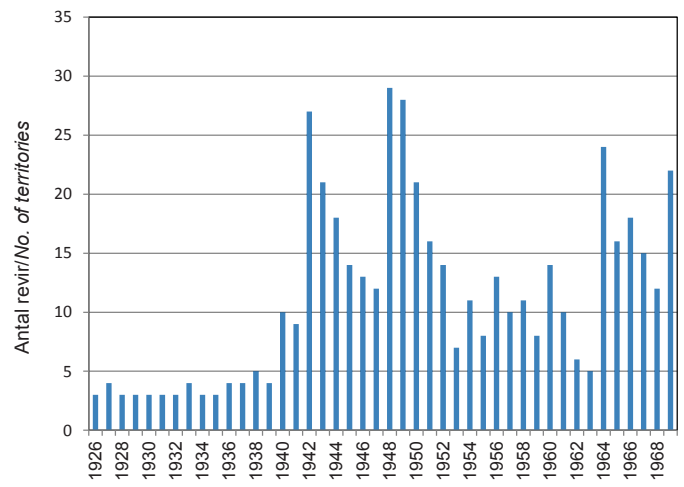

Figur 4. Antalet revirhävdande hannar av svart rödstjärt i London 1926-1969 (efter Meadows 1970).

Number of territory males of Black Redstart in London 1926-1969 (from Meadows 1970). 


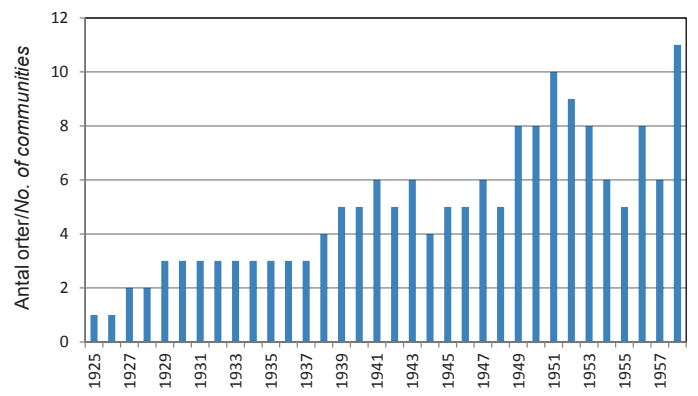

Figur 5. Antal orter i Sverige med rapporterade häckningar av svart rödstjärt 1925-1958 (hämtat från bl.a. Rosenius 1926, Curry-Lindahl 1963).

Number of towns in Sweden with breeding records of Black Redstart 1925-1958.

en huvudsaklig utbredning i de sydöstra delarna av landet (Rosenius 1926, Dybbro 1976).

En likartad utveckling ägde rum i Sverige, där beståndet länge höll sig till synes oförändrat kring ett fåtal par. En uppgång var märkbar under krigsåren, och kring 1949-1950 skedde en kraftig ökning både av antalet par och häckningsplatser (Figur 5, Curry- Lindahl 1963, Dybbro 1976). Vid expansionens inledningsskede dominerade ettåriga hannar som pionjärer, vilket stämmer väl överens med andra studier (Otterlind 1954, Andersson 1995). Då inleddes också en stor expansionsvåg och under en 30-årsperiod spred sig arten över Götaland och Svealand, för att i slutet av 1970-talet i princip ha nått sin nuvarande utbredningsgräns. År 1960 uppskattades det svenska beståndet till cirka 50 par och vid 1970-talets inledning till 100-200 par (Svensson m.fl. 1999, Ottosson m.fl. 2012).

I Norge häckade ett par i Oslo 1923, Österdalen 1941 och Kongsberg 1951-1954 (Haftorn 1971). Utöver konstaterade häckningar gjordes ett flertal ströfynd även långt norrut i Skandinavien.

\section{Diskussion}

Andra världskrigets sönderbombade städer erbjöd av allt att döma optimala och synnerligen gynnsamma betingelser för svarta rödstjärten. Ogräsområden och ruderatmarker bredde ut sig, vilket gynnade födotillgången $\mathrm{i}$ form av insekter. Förekomsten av lämpliga boplatser var närmast oändlig i de trasiga stadskärnorna. Artens kvalitetskrav på födosöksområden och boplatser som har kvantifierats i svenska studier bekräftar att gynnsamhetsgraden var hög i de raserade ruinstäderna (jfr. Andersson 1985, 1987, 1990, 1995, Landmann 1996).

Denna uppsats redovisar ett synkront sprid- ningsförlopp efter andra världskriget i randområden som Storbritannien, Danmark och Sverige. Tillväxttakten i populationen steg drastiskt under och efter krigsåren och en tydlig förändring ägde rum i artens nordeuropeiska utbredning. Mycket talar för att händelseförloppet $\mathrm{i}$ hög grad påverkade spridningen norrut till Skandinavien. I svenska stads- och industrimiljöer var expansionen särskilt påtaglig kring 1949-50, då stadigvarande bestånd etablerades även utanför Skåne. Halland är ett sådant exempel där svarta rödstjärten hållit sig kvar fram till idag (Wirdheim 2014).

Att utvecklingen i kärnområden har stor betydelse för spridningen till mer perifera randpopulationer, finns ett flertal exempel på hos andra arter (Otterlind 1954). Efter en tillbakagång och försvinnande från vissa platser i slutet av 1800-talet, återetablerades rödspoven i delar av Sverige under 1920-talet, i samband med en kraftig numerär tillväxt i de holländska kärnområdena (Cramp 1983, Ahlen \& Tjernberg 1992). Detsamma gällde för skäggmesen som ökade explosionsartat i samband med att stora arealer bladvass bredde ut sig vid invallningarna av holländska Ijsselmeer under 1960-talet (Axell 1966, Björkman \& Tyrberg 1982). Några år senare dök de första exemplaren upp i Sverige. Även sydlig gråsiska gjorde en geografisk framstöt i Danmark och Sverige under 1960-1970-talen, efter planteringar av bergtall i stor skala i nordvästeuropa (Götmark 1981, Ahlen \& Tjernberg 1992). Populationen av svarthuvad mås i Svarta havet formligen exploderade under 1980-talet, från 20000 par till 360000 par. Det ledde till en kraftig expansion i hela Europa, med exempelvis 2000 par i de västliga kärnområdena i Holland (Ardamatskaya 1999). Invandringsvägen har bekräftats av ett flertal återfynd av ringmärkta fåglar i bland annat Danmark (Bonlokke 2006).

Skedstorken är nu inne i ett expansionsskede som ännu inte avslutats och exempelvis uppgår antalen $\mathrm{i}$ Danmark till drygt hundra par. Dessa danska fåglar har sannolikt spridit sig från den Holländska populationen som ökat dramatiskt i storlek (Nyegaard m.fl. 2014). Detsamma gäller för såväl vitstjärnig blåhake som svarthakad buskskvätta, båda med över 300 par i Danmark. Spridningen föregicks av en extrem expansion, för blåhake med siffror på 10000 par i Holland och svarthakad buskskvätta med över 500 par exempelvis i Schleswig-Holstein (Bruns \& Berndt 2002, Hustings m.fl. 2002, Knief m.fl. 2010). Svarta rödstjärtens status efter andra världskriget utgör ytterligare ett exempel på kärnområdets betydelse för utbredningsgränsen och tillväxttakten i randpopulationer (jfr. Haas m.fl. 2014). 
Tack

Ett stort tack till Erik Wallentin, Kåre Ström, Pär Sandberg och Mats Lundberg för granskning av manuskriptet.

\section{Referenser}

Ahlen, I. \& Tjernberg, M. 1992. Artfakta. Sveriges hotade och sällsynta ryggradsdjur. Artdatabanken.

Allard, P.R. 1973. Black Redstart. Transact. Norf. Norwich Nat. soc. 22: 188-190.

Andersson, R. 1985. Svarta rödstjärtens krav på häckningsmiljö. Vår Fågelvärld 44: 224-226.

Andersson, R. 1987. Revirtäthet och populationsstruktur hos ett västsvenskt bestånd av svart rödstjärt Phoenicurus ochruros. Vår Fågelvärld 46: 256-269.

Andersson, R. 1990. Svarta rödstjärtens Phoenicurus ochruros häckningsbiologi i Västsverige. Vår Fågelvärld 49: 201-210.

Andersson, R. 1995. Hannars etableringsmönster, revirkvalitet samt flytande bestånd i en randpopulation av svart rödstjärt Phoenicurus ochruros. Ornis Svecica 5: 143-159.

Ardamatskaya, T.B. 1999. Breeding sites of Mediterranean Gull Larus melanocephalus in the countries of the former Soviet Union. Pp. 97-101 in Proceedings of the 1 st International Mediterranean Gull meeting (Meiniger, P.L., Hogendom, W., Flament, R. \& Raevel, P., eds.) Le Portal, Pas-de-Calais, France.

Axell, H.E. 1966. Eruptions of Bearded Tits during 1959-65. British Birds 59: 513-543.

Björkman, G. \& Tyrberg, T. 1982. Skäggmesen i Sverige 1965-1979. Vår Fågelvärld 41: 73-94.

Bonlokke, J., Madsen, J.J., Thorup, K., Pedersen, K.T., Bjerrum, M. \& Rahbek, C. 2006. Dansk Traekfugleatlas. Rhodos.

Borén, P.G. 1903. Svarta rödstjärten häckande i Skåne. SJFT 41:215-216.

Bruns, H.A. \& Berndt, R.K.. 2002. Aktuelle Verbreitung, Bestandsentwicklung und Habitatwahl des Weissternigen Blaukelchens (Luscinia svecica cyanecula). Corax 19: 93-104.

Cramp, S. 1983. The Birds of the Western Palearctic. Oxford.

Curry- Lindahl, K. 1963. Våra fåglar i Norden. Natur och kultur, Stockholm.

Dybbro, T. 1976. De danske ynglefugles udbredelse. DOF, Kobenhavn.

Fitter, R.S.R. 1955. The spread of the Black Redstart as a breeding species in England. Int. Orn. Congr. 11: 443-445.

Fitter, R.S.R. 1965. The breeding status of the Black Redstart in Great Britain. British Birds 58:481-492.

Friedrich, J. 2008. Branden- Tyskland under bombkriget 1940-1945. Fischer \& Co. München.

Glutz von Blotzheim, U.N. \& Bauer, K.M. 1988. Handbuch der Vögel Mitteleuropas. AULA-Verlag, Wiesbaden.

Götmark, F. 1981. Gråsiskans Carduelis flammea cabaret invandring till södra Sverige: resultat av en inventering 1978. Vår Fågelvärld 40: 47-56.

Haas, F., Barbet-Massin, M., Green, M., Jiguet, F. \& Lindström, A. 2014. Species turnover in the Swedish bird fauna 1850-2009 and a forecast for 2050. Ornis Svecica 24: 106-128.

Haftorn, S. 1971. Norges fugler. Universitetsforlaget, Trondhjem.

Hampel, F. \& Heitkamp, U. 1968. Quantitative Bestandsaufnahme der Brutvögel Göttingens 1965 und ein Vergleich mit fruheren Jahren. Beihäfte der Vogelwelt, Heft 2 (Faunistik und Ökologie): 27-38.

Hustings, F., Vergeer, J-W. \& Eekelder, P. 2002. Atlas von de Nederlandse broedvogels 1998-2000. Nederlandse Fauna 5.

Knief, W., Berndt, R.K., Hälterlein, B., Jeromin, K., Kieckbusch, J.J. \& Koop, B. 2010. Die Brutvögel SchleswigHolsteins. Ministerium fur Landwirtschaft, Umwelt und ländliche Räume des Landes Schleswig-Holstein.

Landmann, A. 1996. Der Hausrotschwanz. AULA- Verlag, Wiesbaden.

Lemke, W. 1965. Zum Vorkommen des Hausrotschwanzes in Hamburg. Vogel und Heimat 14: 345-347.

Malling Olsen, K. 1992. Danmarks Fugle. DOF.

Meadows, B.S. 1970. Breeding distribution and feeding ecology of the Black Redstart in London. London Bird Report 34: 72-79.

Morgan, R.A. \& Glue, D.E. 1981. Breeding survey of Black Redstarts in Britain 1977. Bird Study 28: 163-168.

Muller, E. 1969. Hausrotschwanz, in J. Peitzmeier; Avifauna von Westfalen. Landesmuseum fur Naturkunde, Munster.

Nyegaard, T., Meltofte, H., Tofft, J. \& Borch Grell, M. 2014. Truede og sjeldne ynglefugle i Danmark 1998-2012. Dansk Ornitologisk Forenings Tidsskrift 108: 1-144.

Otterlind, G. 1954. Flyttning och utbredning. Ett bidrag till kännedomen om den Skandinaviska fågelfaunans utbredningsdynamik. Vår Fågelvärld 13: 1-31, 83-113, 147-167, 245-261.

Ottosson, U., Ottvall, R., Elmberg, J., Green, M., Gustafsson, R., Haas, F., Holmqvist, N., Lindström, Å., Nilsson, L., Svensson, M., Svensson, S. \& Tjernberg, M. 2012. Fåglarna i Sverige- antal och förekomst. SOF, Halmstad.

Peus, F. 1952. Steppenvögel mitten in Berlin. Die Vogelwelt $73: 1$.

Rosenius, P. 1926. Sveriges fåglar och fågelbon. Gleerups, Lund.

Schmidt, G. 1953. Von den Auswirkungen des Bombenkrieges auf die Ökologie der Vögel der stadt Kiel. Die Vogelwelt 74: 141-142.

Schumann, H. 1956. Die Folgen von Kriegsverwustungen und Wiederaufbau fur den Vogelbestand der Stadt Hannover. Nat. u. Jagd in Niedersachsen: 192-195.

Svensson, S., Svensson, M. \& Tjernberg, M. 1999. Svensk fågelatlas. Vår Fågelvärld, supplement 31, Stockholm.

Witherby, H.F. \& Fitter, R.S. 1942. Black Redstart in England in the summer of 1942. British Birds 36: 132-139.

Timmermann, G. 1953. Die Vogelwelt des Hamburger Wandergebietes. Hamburg.

Vleugel, D.A. 1960a. Waarnemingen betreffende de arealmitbreiding van de Zwarte Roodstaart in ons land 194250. Limosa 33: 6-18.

Vleugel, D.A. 1960b. Het voorkommen van de Zwarte Roodstaart in mest en Nord-Nederland. Natura Amst. 57: 73-74.

Wirdheim, A. 2014. Hallands fågelatlas. HallOF, Halmstad.

Wittenberger, J. 1976. Zum Brutvorkommen des Hausrotschwanzes Phoenicurus ochruros im Hamburger Raum. Hamb. Avifauna. Beitr. 14: 27-46. 
Wendland, V. 1971. Die Wirbeltiere Westberlins. Duncker \& Humblot, Berlin.

Wust, W. 1970. Die Vogelwelt der Landeshauptstadt Munchen. Munchen.

\section{Summary}

The Black Redstart Phoenicurus ochruros was a scarce breeder in northern Germany in the 1880s. In UK and Scandinavia the population was at a constant low level during the 1940s. The conditions changed dramatically when cities, bombed and ruined during the Second World War, offered seemingly optimal habitats for the Black Redstart. Weeded areas were common which favoured food availability in the form of insects. The number of suitable nesting sites was almost infinite in the broken city centres. This literature review summarizes how bombed cities during the Second World War may have facilitated the expansion of Black Redstart from Central Europe and influenced the distribution pattern in northern Europe. The study is focused on how important the development in the core areas is for the spreading of Black Redstart to more peripheral populations. A large number of photographs of the bombed cities were studied, in order to get a more detailed picture of how important the habitats may have been for Black Redstart feeding, nesting and protection. The species was reported as a breeder in ruins in several German, Dutch and English cities. Compared to studies of Black redstarts in Sweden, where habitat quality was quantified, the bombed cities most certainly held habitats of considerably higher quality. There was a synchronous change in distribution of the species into previously peripheral regions in Britain, Denmark and Sweden. The growth rate in the Black Redstart population increased dramatically during and after the war and a clear change took place in the distribution of the species in northern Europe. In general terms the development in core areas of a species may be of great importance for the spreading to more peripheral populations, which has been showed in other species, such as Black-tailed Godwit Limosa limosa, Bearded Tit Panurus biarmicus, Lesser Redpoll Carduelis flammea cabaret, Mediterranean Gull Larus melanocephalus, Spoonbill Platalea leucorodia, White-spotted Bluethroat Luscinia svecica cyanecula and European Stonechat Saxicola torquatus. 